\title{
Risk factors associated with postmenopausal bleeding and endometrial carcinoma.
}

1. MBBS, FCPS

Assistant Professor Gynaecology and Obstetrics

Foundation University Medical

College

Foundation University, Islamabad.

2. MBBS, FCPS

Assistant Professor Rehabilitation Sciences

Foundation University Institute of Rehabilitation Sciences

Foundation University Islamabad.

3. M.Phil (Biochemistry)

Lecture

Riphah College of Rehabilitation

Sciences,

Riphah International University, Islamabad.

4. MBBS, MCPS

Senior Registrar Gynaecology and Obstetrics

Foundation University Medical

College

Foundation University, Islamabad.

5. MBBS, FCPS, MRCOG

Assistant Professor Gynaecology and Obstetrics

Foundation University Medical College

Foundation University, Islamabad.

6. MBBS, FCPS

Senior Registrar Gynaecology and Obstetrics

Foundation University Medical

College

Foundation University Islamabad.

Correspondence Address:

Dr. Nadia Ahmed Bukhari

Department of Gynaecology and

Obstetrics

Foundation University Medical College

Foundation University, Islamabad.

nadia67bukhari@hotmail.co.uk

Article received on:

11/09/2019

Accepted for publication:

25/01/2020

\section{INTRODUCTION}

Endometrial cancer is considered as the most frequent gynecologic cancer in developed countries and accounts for about $5 \%$ of total cancer with death rate of approximately $2 \%$ in women globally. ${ }^{1}$ The prevalence of endometrial cancer is predominantly high in some regions such as North America and areas of Europe, in contrast to other developed countries, which may be recognized endometrial carcinoma.
Nadia Ahmed Bukhari', Wardah Ajaz Qazi ${ }^{2}$, Saira Jahan ${ }^{3}$, Sadia Asmat ${ }^{4}$, Nosheen Akhter ${ }^{5}$, Robina Jabeen ${ }^{6}$

RACT... Objective: The objectives of the study were to identify the common causes of post menopausal bleeding, benign and malignant causes of post menopausal bleeding and also the identification of risk factors for endometrial carcinoma in women with postmenopausal bleeding. Study Design: Cross sectional survey. Setting: Fauji Foundation Hospital Rawalpindi. Period: August 2018 to January 2019. Material \& Methods: A total of 224 women with post menopausal bleeding were included in this study. Data was collected through the self structured questionnaire in which we have included patient's demographics, risk factors of Post menopausal bleeding and risk factors of endometrial carcinoma. Histopathological investigations of endometrial sampling were done for identification of benign and malignant causes of post menopausal bleeding. Results: Mean age of the women was 59.17 years and mean parity was found to be 2.24 . Out of 224 patients $106(47.3 \%)$ women had their menopause in duration of 6 to 10 years while 75(33.9\%) had menopause in time duration of first 5 years showing high frequency trend of post menopausal bleeding in first ten years duration after menopause. Out of 224 patients 30(13.4) were of normal weight, 94(42.0) were overweight while 100(44.6) were obese according to BMI criteria. Endometrial carcinoma was found in 40 women with post menopausal bleeding. Among them age at menarche was found to be 9 to 13 years in $27(67.5 \%)$ patients while more than 13 years in $13(32.5 \%)$ women. Age at menopause was found more than 55 years in 20(50\%) patients while less than 55 years also in $20(50 \%)$ patients. Personal history of breast carcinoma was reported in $6(15 \%)$ similarly family history was also found in 6(15\%) women. Family history of CA endometrium was observed in $3(7.5 \%)$. History of PCOs was also observed in 5(12.5) patients. Menstrual irreguraity in perimenopausal period was found in $18(45 \%)$ patients with endometrial CA. Nulliparity was reported in $21(52.5 \%)$ patients. $12(30 \%)$ were on estrogen use while 4(10\%) were on Tamoxifen use. Conclusion: Diabetes Mellitus and Hypertension were observed as common risk factors for post menopausal bleeding. Endometrial Carcinoma, cervix carcinoma and Hyperplasia with atypia were common malignant causes while endometrial polyp and fibroid uterus were commonly found benign causes of post menopausal bleeding. Early menarche, menopausal duration of more than one year, obesity and diabetes mellitus were common risk factors for

Key words: $\quad$ Post menopausal Bleeding, Endometrial Carcinoma, Risk Factors, Benign and Malignant Causes.

Article Citation: Bulhari NA, Qazi WA, Jahan S, Asmat S, Akhter N, Jabeen R. Risk factors associated with postmenopausal bleeding and endometrial carcinoma. Professional Med J 2021; 28(2):208-213. https://doi.org/10.29309/TPMJ/2021.28.02.3447 to other remarkable risk factors for instance early menarche, late menopause, nulliparity, aging, postmenopausal treatment of estrogen therapy. ${ }^{2}$ On the contrary to most cancers, the incidence of endometrial cancer and associated death rates have increased considerably in recent years ${ }^{3-5}$ and also anticipated to increase during the period of next 10 years. ${ }^{6-8}$ 
Worldwide prevalence of endometrial cancer is 9 for every 100000 women, with a life span risk of $1 \%$, unopposed estrogen exposure is a worth mentioning risk factor involved, where prolonged exposure cause persistent endometrial proliferation and perhaps, endometrial carcinoma. ${ }^{9}$ Various other risks factor influence estrogen exposure involved obesity, polycystic ovarian syndrome, anovulation, nulliparity and diabetes mellitus type $1 .^{10}$ and these are also familiar to augment the risk of endometrial carcinoma. In some conditions, an irregular excessive proliferation of endometrial glands, endometrial hyperplasia, may be consider a reason for developing endometrial carcinoma. 'Atypical' hyperplasia pose the highest risk and, as with endometrial cancer, is treated by hysterectomy. ${ }^{11}$

Endometrial carcinoma clinically manifested with postmenopausal bleeding (PMB).${ }^{10}$ therefore it is recommended that women presenting with $\mathrm{PMB}$ are referred for further evaluation. ${ }^{12,13}$

To rule out the endometrial carcinoma, the possible indicators for biopsy is controversial ${ }^{14}$ and current guidance vary. Current guidelines suggest an age cutoff, above which patients are referred; in some it is consider as 40 years. ${ }^{15}$

For early detection of endometrial carcinoma could focus on females at high risks of developing endometrial cancer, while excluding most women at lower risks. Most common symptom of endometrial cancer is postmenopausal bleeding (PMB) and accounts for about two-thirds of all gynecologic visits amongst perimenopausal and postmenopausal women. ${ }^{16,17}$ Even though, PMB is commonly associated with endometrial polyps or/and might result from spontaneous bleeding in women treating with hormone therapy. ${ }^{18}$ In some studies, the risks of developing endometrial cancer in females with post menopausal bleeding vary widely from $3 \%$ to $25 \% .{ }^{19,20}$ Most endometrial cancer is diagnosed at a localized stage and is usually treatable with surgery, with a -year survival rate of about $95 \%$. In comparison, 5-year survival rate for stage IV (late stage) endometrial cancer range from $16 \%$ to $45 \%$. $^{21,22}$
The objective of this study was to determine the risk factors associated with endometrial carcinoma in women with postmenopausal bleeding and to identify the benign and malignant causes of post menopausal bleeding.

\section{MATERIAL \& METHODS}

This cross sectional survey was carried out from August 2018 to January 2019 at Fauji Foundation Hospital, Rawalpindi. In this study a total of 224 women with post menopausal bleeding were included. Sample size was calculated by using Raosoft software keeping in view 5\% margin of error, $95 \%$ of confidence interval, 20000 population size with $50 \%$ response distribution. Written informed consent was taken from the patients. Ethical consent was taken from Ethical review committee.

Data was collected through the self designed structured questionnaire in which we have included patient's demographics, risk factors of Post menopausal bleeding and risk factors of endometrial carcinoma. Histopathological investigations of endometrial sampling were done for identification of benign and malignant causes of post menopausal bleeding.

\section{RESULT}

Mean age of the women was 59.17 years and mean parity was found to be 2.24 . Out of 224 patients 106(47.3\%) women had their menopause in duration of 6 to 10 years while $75(33.9 \%)$ had menopause in time duration of first 5 years showing high frequency trend of post menopausal bleeding in first ten years duration after menopause. Out of 224 patients 30(13.4) were of normal weight, 94(42.0) were overweight while 100(44.6) were obese according to BMI criteria. When asked about hormonal treatment $67(29.9 \%)$ were on contraceptive use, $24(10.7 \%)$ were on HRT, 67(29.9\%) were taking drugs for menstrual regularity while $20(8.9 \%)$ were on ovulation induction. Regarding the duration of post menopausal bleeding, 144(64.3\%) had it for less than 1 year while $79(35.3 \%)$ had it for more than 1 year. According to the management, $\mathrm{TAH}+\mathrm{BSO}$ done in 113(50.4) patients while 27(12.1) received oncology treatment, in 6(2.7) marina insertion 
done, 28(12.5) received oral hormonal treatment and 48(21.4) were on conservative management.

Endometrial carcinoma was found in 40 women with post menopausal bleeding. Among them age at menarche was found to be 9 to 13 years in $27(67.5 \%)$ patients while more than 13 years in $13(32.5 \%)$ women. Age at menopause was found more than 55 years in $20(50 \%)$ patients while less than 55 years also in 20(50\%) patients. Personal history of breast carcinoma was reported in $6(15 \%)$ similarly family history was also found in $6(15 \%)$ women. Family history of endometrium carcinoma was observed in $3(7.5 \%)$. History of PCOs was also observed in 5(12.5) patients.

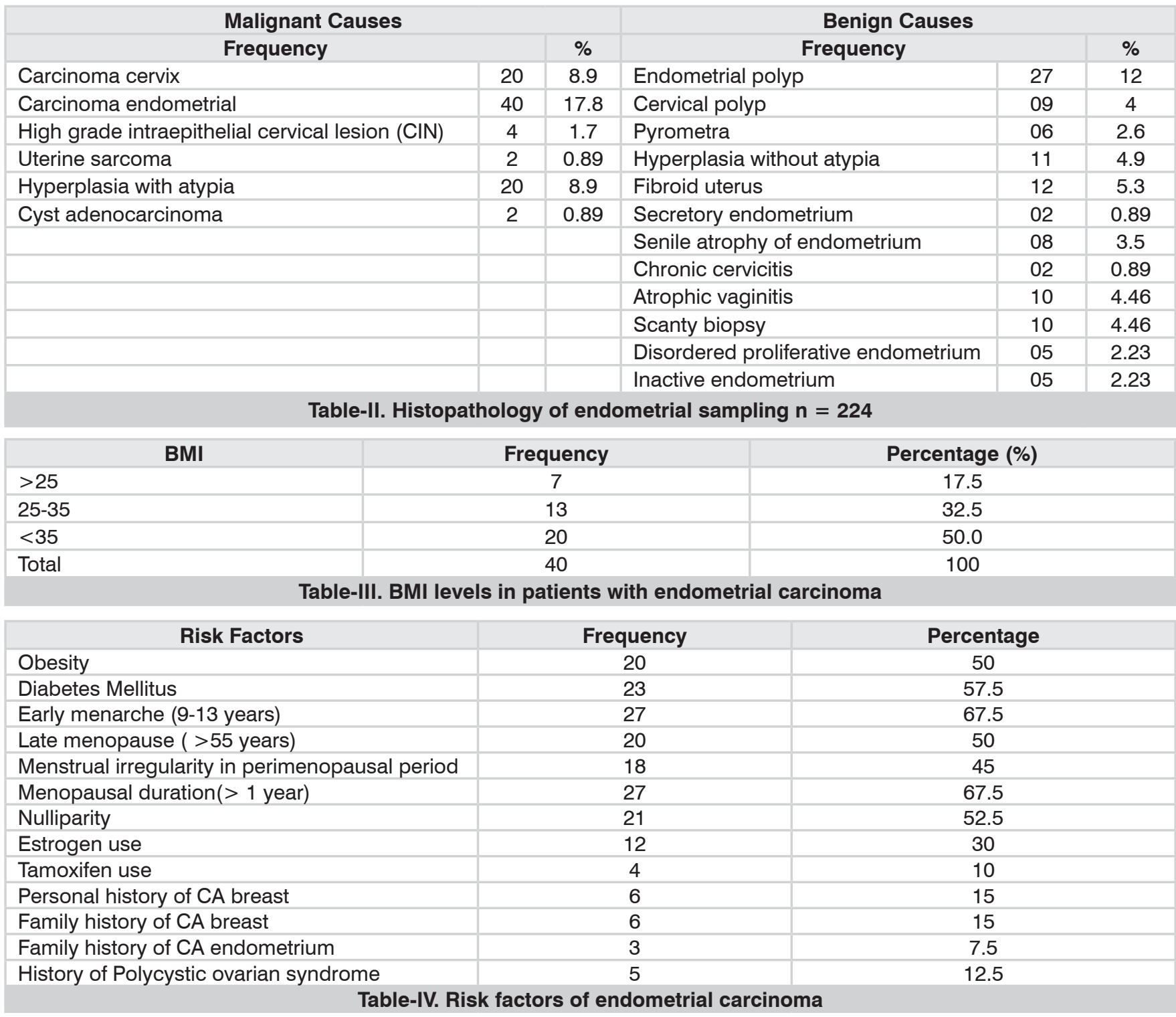

Menstrual irregularity in perimenopausal period was found in $18(45 \%)$ patients with endometrial carcinoma. Nulliparity was reported in 21 (52.5\%) patients. $12(30 \%)$ were on estrogen use while $4(10 \%)$ were on Tamoxifen use.

\begin{tabular}{|l|c|c|}
\hline \multicolumn{1}{|c|}{ Conditions } & Frequency & Percentage (\%) \\
\hline Diabetes mellitus & 63 & 28.1 \\
\hline Hypertension & 70 & 31.3 \\
\hline Smoking & 27 & 12.1 \\
\hline History of tumor & 19 & 8.5 \\
\hline HCV positive & 25 & 11.2 \\
\hline Thyroid disease & 14 & 6.3 \\
\hline No co morbidity & 4 & 1.7 \\
\hline Total & 224 & 100 \\
\hline
\end{tabular}

Table-I. Risk factors for post menopausal bleeding Benign Causes 


\section{DISCUSSION}

American Cancer Society documented in 2001 that there were an inadequate details to suggest screening for endometrial cancer in females at average or increased risks due to history of diabetes, hypertension, infertility, obesity, late menopause, nulliparity, tamoxifen or unopposed estrogen therapy. ${ }^{23}$ At the stage of menopause every woman should be informed about the risk factors and symptoms of endometrial cancer and highly appreciated to document any unexpected bleeding to their clinicians. ${ }^{24}$

$\mathrm{KJ}$ Jung et al. have documented that, in western world early menarche, late menopause and long period between menarche and menopause were significantly associated with a high risk of developing breast cancer. For endometrial carcinoma, there was a statistically significant trend with the duration between menarche and menopause. ${ }^{25}$

Menarche is an event referring the commencement of female reproductive cycle. Increasing evidence suggested the importance of menarche as both a footprint for chronic disease risks and a compass for developmental trajectory and overall health status. Unfavorable effect due to earlier age at menarche embrace risks for developing breast ${ }^{26,27}$ and endometrial cancer ${ }^{28}$ In our study early menarche was found in $67.5 \%$ women. Our study confirm the findings of previous studies demonstrating that an earlier age at menarche was associated with increased risk of developing endometrial cancer (Table-II).

Menopause is considered as the permanent cessation of ovulation and menstruation, the final menstrual period definite by the subsequent 12 successive months in an absence of menses. It depicts the loss of reproductive capability, and the menopausal age is an indicator for overall health

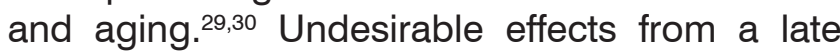
menopausal age comprise risks for developing endometrial and breast cancer. ${ }^{31,32} \mathrm{~A}$ European prospective investigation demonstrated a strong protective association with the use of oral contraceptives, parity and ovarian cancer risk, a high risk of advance age at menopause, and no association with other reproductive factors. Our study is in keeping with reports from previous studies in finding that an advance age at menopause was associated with an increased risk of developing endometrial cancer. Our study confirms the findings of previous studies demonstrating that advance age at menopause was associated with high risk of endometrial carcinoma, as our study documented $50 \%$ women with late menopause (Table-II).

Several other studies have demonstrated the role of reproductive factors - such as age at menarche, parity, lactation and menopause, - on the risk for the development of hormonerelated cancers, including breast cancer and ovarian cancer. ${ }^{33}$ Our study is consistent with this hypothesis, demonstrating that about a 10year increase in the duration of menopause was associated with around a two-fold increase in the risk of endometrial carcinoma.

\section{CONCLUSION}

Diabetes Mellitus and Hypertension were observed as common risk factors for post menopausal bleeding. Endometrial Carcinoma, cervix carcinoma and Hyperplasia were common malignant causes while endometrial polyp and fibroid uterus were commonly found benign causes of post menopausal bleeding. Early menarche, menopausal duration of more than one year, obesity and diabetes mellitus were common risk factors for endometrial carcinoma.

Copyright $\odot 25$ Jan, 2020.

\section{REFERENCES}

1. Ferlay, J., et al., Cancer incidence and mortality worldwide: Sources, methods and major patterns in GLOBOCAN 2012. International journal of cancer, 2015. 136(5): p. E359-E386.

2. Setiawan, V.W., et al., Type I and II endometrial cancers: Have they different risk factors? Journal of Clinical Oncology, 2013. 31(20): p. 2607.

3. Torre LA, Islami F, Siegel RL, Ward EM, Jemal A. Global Cancer in Women: Burden and Trends. Cancer Epidemiol Biomarkers Prev. 2017 Apr;26(4):444-457. doi: 10.1158/1055-9965.EPI-16-0858. Epub 2017 Feb 21. PMID: 28223433. 
4. Siegel, R.L., K.D. Miller, and A. Jemal, Cancer statistics, 2017. CA: A cancer journal for clinicians, 2017. 67(1): p. 7-30.

5. Lortet-Tieulent, J., et al., International patterns and trends in endometrial cancer incidence, 1978-2013. JNCl: Journal of the National Cancer Institute, 2017. 110(4): p. 354-361.

6. Gaber, C., et al., Endometrial cancer trends by race and histology in the USA: Projecting the number of new cases from 2015 to 2040. Journal of racial and ethnic health disparities, 2017. 4(5): p. 895-903.

7. Sheikh, M.A., et al., USA endometrial cancer projections to 2030: Should we be concerned? Future oncology, 2014. 10(16): p. 2561-2568.

8. Smittenaar, C., et al., Cancer incidence and mortality projections in the UK until 2035. British journal of cancer, 2016. 115(9): p. 1147.

9. Sweet, M.G., et al., Evaluation and management of abnormal uterine bleeding in premenopausal women. American family physician, 2012. 85(1).

10. Colombo, N., et al., Endometrial cancer: ESMO Clinical Practice Guidelines for diagnosis, treatment and follow-up. Annals of oncology, 2013. 24(suppl_6): p. vi33-vi38.

11. No, G.-t.G., Management of endometrial hyperplasia.

12. Wright, J.D., et al., Patterns of specialty-based referral and perioperative outcomes for women with endometrial cancer undergoing hysterectomy. Obstetrics and gynecology, 2017. 130(1): p. 81.

13. Cancer, N.C.C.f., Suspected cancer: Recognition and referral. 2015.

14. Iram, S., P. Musonda, and A.A. Ewies, Premenopausal bleeding: When should the endometrium be investigated?-A retrospective non-comparative study of $\mathbf{3 0 0 6}$ women. European journal of obstetrics \& Gynecology and reproductive biology, 2010. 148(1): p. 86-89.

15. Singh, S., et al., Abnormal uterine bleeding in premenopausal women. Journal of Obstetrics and Gynaecology Canada, 2013. 35(5): p. 473-475.

16. Yasa, C., et al., Evaluation of the diagnostic role of transvaginal ultrasound measurements of endometrial thickness to detect endometrial malignancy in asymptomatic postmenopausal women. Archives of gynecology and obstetrics, 2016. 294(2): p. 311-316.
17. Clarke, M.A., et al., Association of endometrial cancer risk with postmenopausal bleeding in women: $A$ systematic review and meta-analysis. JAMA internal medicine, 2018. 178(9): p. 1210-1222.

18. Burbos, N., et al., Postmenopausal vaginal bleeding in women using hormone replacement therapy. Menopause international, 2012. 18(1): p. 5-9.

19. van Doorn, H.C., et al., The relation between age, time since menopause, and endometrial cancer in women with postmenopausal bleeding. International Journal of Gynecological Cancer, 2007. 17(5): p. 1118-1123.

20. Burbos, N., et al., Management of postmenopausal women with vaginal bleeding when the endometrium can not be visualized. Acta obstetricia et gynecologica Scandinavica, 2012. 91(6): p. 686-691.

21. Weiderpass, E., et al., Trends in corpus uteri cancer mortality in member states of the European Union. European Journal of Cancer, 2014. 50(9): p. 1675-1684.

22. Beller, U., et al., Carcinoma of the vagina. FIGO 26th Annual Report on the Results of Treatment in Gynecological Cancer. International journal of gynaecology and obstetrics: the official organ of the International Federation of Gynaecology and Obstetrics, 2006. 95: p. S29-42.

23. Smith, R.A., et al., American Cancer Society guidelines for the early detection of cancer: update of early detection guidelines for prostate, colorectal, and endometrial cancers: Also: update 2001-testing for early lung cancer detection. CA: a cancer journal for clinicians, 2001. 51(1): p. 38-75.

24. Smith, R.A., et al., Cancer screening in the United States, 2017: A review of current American Cancer Society guidelines and current issues in cancer screening. CA: a cancer journal for clinicians, 2017. $67(2)$ : p. 100-121.

25. Jung, K.J., et al., Duration of ovarian hormone exposure and gynecological cancer risk in Korean women: The Korean Heart Study. Cancer epidemiology, 2016. 41: p. 1-7.

26. Jee, S.H., et al., A coronary heart disease prediction model: The Korean Heart Study. BMJ open, 2014. 4(5): p. e005025.

27. Jee, S.H., et al., Cardiovascular disease risk factors in relation to suicide mortality in Asia: prospective cohort study of over one million Korean men and women. European Heart Journal, 2011. 32(22): p. 27732780 . 
28. Hamilton, A.S. and T.M. Mack, Puberty and genetic susceptibility to breast cancer in a case-control study in twins. New England Journal of Medicine, 2003. 348(23): p. 2313-2322.

29. Golub, M.S., et al., Public health implications of altered puberty timing. Pediatrics, 2008. 121(Supplement 3): p. S218-S230.

30. Dossus, L., et al., Reproductive risk factors and endometrial cancer: The European Prospective Investigation into Cancer and Nutrition. International journal of cancer, 2010. 127(2): p. 442-451.
31. Choi, Y., et al., Age-period-cohort analysis of female breast cancer mortality in Korea. Cancer research and treatment: official journal of Korean Cancer Association, 2016. 48(1): p. 11.

32. Sherman, S., Defining the menopausal transition. The American journal of medicine, 2005. 118(12): p. 3-7.

33. Gold, E.B., The timing of the age at which natural menopause occurs. Obstetrics and Gynecology Clinics, 2011. 38(3): p. 425-440.

\begin{tabular}{|c|c|c|c|}
\hline \multicolumn{4}{|c|}{ AUTHORSHIP AND CONTRIBUTION DECLARATION } \\
\hline Sr. \# & Author(s) Full Name & Contribution to the paper & Author(s) Signature \\
\hline 1 & Nadia Ahmed Bukhari & $\begin{array}{l}\text { Conceived the study and } \\
\text { designed the model. }\end{array}$ & \\
\hline 2 & Wardah Ajaz Qazi & $\begin{array}{l}\text { Carried out the survey, } \\
\text { manuscript search. }\end{array}$ & \\
\hline 3 & Saira Jahan & $\begin{array}{l}\text { Did the literature search, } \\
\text { analyzed the data. }\end{array}$ & \\
\hline 4 & Sadia Asmat & $\begin{array}{l}\text { Did the literature search, } \\
\text { analyzed the data. }\end{array}$ & \\
\hline 5 & Nosheen Akhter & $\begin{array}{l}\text { Analyzed the data, performed } \\
\text { the calcualtions. }\end{array}$ & \\
\hline 6 & & $\begin{array}{l}\text { Performed the calculations, } \\
\text { Manuscript writing. }\end{array}$ & 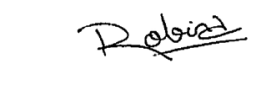 \\
\hline
\end{tabular}

